\title{
Phytochemistry and inflorescences morphometry of Invasive Solidago L. (Goldenrods) species - valuable late autumn mellifers
}

\author{
Olga Shelepova, Yulia Vinogradova* \\ N.V. Tsitsin Main Botanical Garden of Russian Academy of Sciences, Moscow, Russia \\ ORCID \\ Olga Shelepova: https://orcid.org/0000-0003-2011-6054 \\ Yulia Vinogradova: https://orcid.org/0000-0003-3353-1230
}

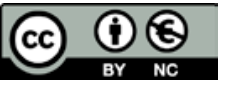

Article Details:

Received: 2021-06-26

Accepted: 2021-07-18

Available online: 2021-11-30

DOI: https://doi.org/10.15414/ainhlq.2021.0019

\begin{abstract}
In Europe, two invasive North American species of Solidago L. have been detected: S. canadensis L. and S. gigantea Ait. Both species provide a stable late harvest and are valued by beekeepers for their ability to produce pollen and nectar in late fall. There is a significant correlation between the chemical components of flowers and goldenrod honey, so the study of the phytochemical composition of inflorescences (heads) seems to be very actual. The work aims to determine the total content of saccharides, phenolic compounds, and flavonoids in the heads of S. canadensis and S. gigantea for comparative evaluation of bee production quality, and also to specify morphometric differences in the heads of both species and to reveal the amplitude of their variability. The material was collected in the Moscow and Pskov Regions (Russia). The total content of the saccharides in S. canadensis heads was $27.33 \pm 0.54 \%$, with monosaccharides 44-46 \%. In S. gigantea's heads total content of the saccharides was 1.5 times lower $-18.07 \pm 0.73 \%$, the content of monosaccharides was $7.39 \pm 0.15 \%$. The total content of phenolic compounds in the heads of S. canadensis was $105.36 \pm 1.45 \mathrm{mg} \mathrm{GAE} / 100 \mathrm{~g}$ and in $S$. gigantea's heads was $98.41 \pm 1.71 \mathrm{mg} \mathrm{GAE} / 100 \mathrm{~g}$. The total flavonoid content as quercetin equivalents was $58.23 \pm 0.17 \mathrm{mg} \mathrm{QE} / 100 \mathrm{~g}$ in the heads of $S$. canadensis and $41.97 \pm 0.34 \mathrm{mg} \mathrm{QE} / 100 \mathrm{~g}$ in S. gigantea's heads. Thus, in S. canadensis heads the content of the total content of saccharides is 1.5 times higher, the content of phenolic compounds is 1.3 times higher, and the content of flavonoids is 1.4 times higher than in S. gigantea. A feature allowing the diagnosis of these species is the size of the heads: $S$. canadensis has smaller heads than $S$. gigantea $(4.4 \times 1.8$ vs. $6.4 \times 2.3 \mathrm{~mm})$.
\end{abstract}

Keywords: Solidago, flowers, heads, saccharides, phenolic compounds, flavonoids

\section{Introduction}

In Europe, two alien North American species of Solidago L. of the Triplinervae section are detected: S. canadensis L. and S. gigantea Ait. (especially well when growing in homogeneous conditions of the experimental plot). The species differ in morphological characters as well.
S. canadensis has pubescent shoots, short rhizomes, spreading panicles, and toothed leaves. S. gigantea has glabrous shoots (except for the panicle axis), long rhizomes, compact panicle, finely serrated or smoothmargin leaf blades (Figure 1). The species also differ in morphometric features of the heads, but no statistical

\footnotetext{
*Corresponding Author: Yulia Vinogradova, N.V. Tsitsin Main Botanical Garden of Russian Academy of Sciences, Botanicheskaya, 4, 127276 Moscow, Russia $\triangle$ gbsad@mail.ru
} 
analysis of these parameters has been carried out so far.

Both Solidago species are aggressive plants that actively disperse in ruderal habitats, meadows, pastures, fields, forests, roadsides, riverbanks, etc. (Vinogradova et al., 2010). Both species are recognized as invasive weeds that reduce natural biodiversity by displacing native plants (The most..., 2018). The ecological risks that both Solidago species pose to the environment are of great concern. However, there is another, positive value of S. canadensis and S. gigantea, manifesting themselves in their use as sources of valuable raw materials with high added value. Thus, both species provide a stable late harvest and are valued by beekeepers for their ability to produce pollen and nectar in the late fall. This variety of honey is rarely pumped because all of the nectar and pollen go to support the bee colonies and prepare them for wintering. According to the Canadian and Polish experience, goldenrod honey yields up to $150 \mathrm{~kg}$ per hectare - the same amount as sunflowers. Germacren D, which has not been identified in other monofloral kinds of honey, is present in goldenrod honey (Amtmann, 2009).

Although there is no complete similarity between the chemical components of Solidago flowers and goldenrod honey (Amtmann, 2009), there is a significant correlation. Honey absorbs the medicinal qualities of the plant from which it is collected, so the study of the phytochemical composition of inflorescences (heads) seems very actual.

The work aims to determine the total content of saccharides, phenolic compounds and flavonoids in heads of S. canadensis and S. gigantea for comparative evaluation of bee production quality, and also to specify morphometric differences in the structure of flowers and heads of both species and to reveal the amplitude of their variability.

\section{Material and methodology}

\section{Biological material}

Samples of S. canadensis and S. gigantea collected in local invasive populations in Moscow, Moscow Region, and Pskov Region were included in the study. Plants were collected during the beginning of flowering, and the collected samples were dried in bundles suspended in the air at room temperature in a shady place. Only inflorescences (heads), without panicle tips, were used in the phytochemical analysis. For comparative evaluation of morphometric traits, plants growing in the same agrophone were selected.
Studied samples:

1. S. canadensis (Moscow, Main Botanical garden, $\left.55^{\circ} 50^{\prime} 21.3^{\prime \prime} \mathrm{N} 37^{\circ} 35^{\prime} 09.5^{\prime \prime} \mathrm{E}\right)$,

2. S. gigantea (Moscow, Main Botanical garden,

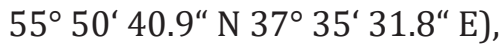

3. S. canadensis (Moscow Region, Zvenigorod, $55^{\circ} 42^{\prime} 11.6^{\prime \prime} \mathrm{N} \mathrm{36} 46^{\circ} 29.6^{\prime \prime} \mathrm{E}$ ),

4. S. gigantea (Moscow Region, Zvenigorod, $55^{\circ} 42^{\prime} 16.7^{\prime \prime} \mathrm{N} 36^{\circ} 46^{\prime} 29.6^{\prime \prime} \mathrm{E}$ ),

5. S. canadensis (Pskov Region, Izborsk, $57^{\circ} 43^{\prime} 16.4^{\prime \prime} \mathrm{N} 27^{\circ} 52^{\prime} 11.3^{\prime \prime} \mathrm{E}$ ).

\section{Determination of total saccharides content and water-soluble carbohydrates}

The content of water-soluble carbohydrates and total saccharides content were determined according to the methods "Determination of sugars by spectrophotometric method" (OFS.1.2.3.0019.15 Gosudarstvennaya, 2015) and "Method for determining the content of water-soluble carbohydrates and starch from one sample" (Patent RU 2406293 C1). The results were expressed in milligrams per $100 \mathrm{~g}$ of air-dry material.

\section{Determination of total polyphenol content (TPC)}

The total polyphenol content (TPC) was measured by the method "Method for determining the total content of phenolic compounds in plant samples" (Patent RU 2700787 C1) using the Folin-Ciocalteu reagent. The samples were prepared and analysed as follows: $0.5 \mathrm{~g}$ of the plant sample was ground with $15 \mathrm{~mL}$ of $96 \%$ ethanolic solution, extraction was carried out for 45 minutes in a water bath, followed by centrifugation. A quantity of $0.75 \mathrm{~mL}$ of each sample was mixed with $0.75 \mathrm{~mL}$ of the Folin-Ciocalteu reagent (diluted 5 times), $1.5 \mathrm{~mL}$ of $20 \%(\mathrm{w} / \mathrm{v}$ ) sodium carbonate, and $7 \mathrm{~mL}$ of distilled water. After $60 \mathrm{~min}$ in darkness, the absorbance at $725 \mathrm{~nm}$ was measured with the spectrophotometer Spekol (1300, Analytik Jena, Germany). Gallic acid (25-300 mg/L; $\left.\mathrm{R}^{2}=0.998\right)$ was used as the standard. The results were expressed in $\mathrm{mg} / \mathrm{g}$ DM gallic acid equivalent.

\section{Determination of total flavonoid content}

The total flavonoid content (TFC) was determined by the method of the GF XIII ed., (p. 332), art. "Grass of Persicaria hydropiper (L.) Delarbre“. Plant samples $(0.5 \mathrm{~g})$ were extracted with an $80 \%$ solution of ethanolic solution for 60 minutes in a water bath with a reverse refrigerator. An aliquot of $2 \mathrm{~mL}$ of the sample was mixed with $1 \mathrm{~mL}$ of $1 \%(\mathrm{w} / \mathrm{v})$ ethanolic solution 

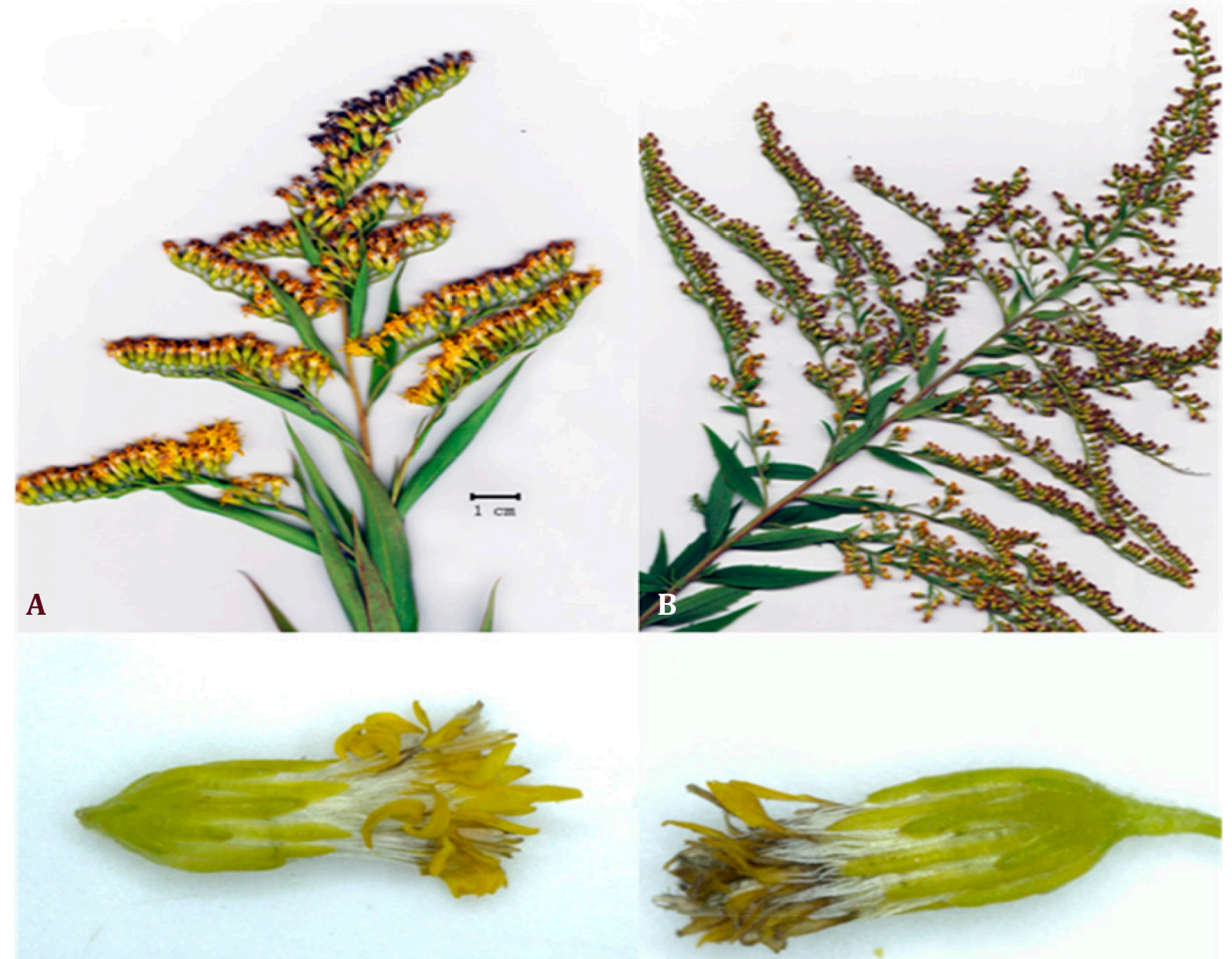

C

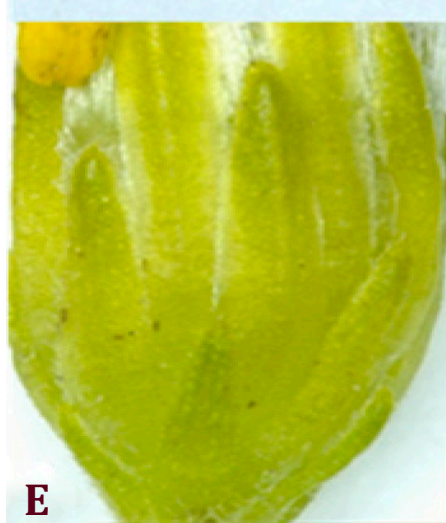

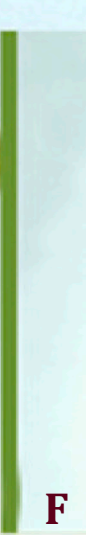

D

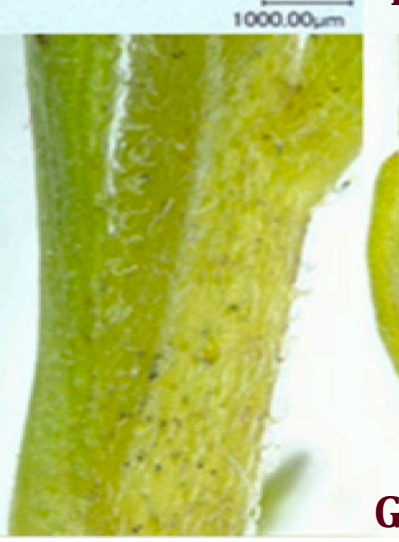

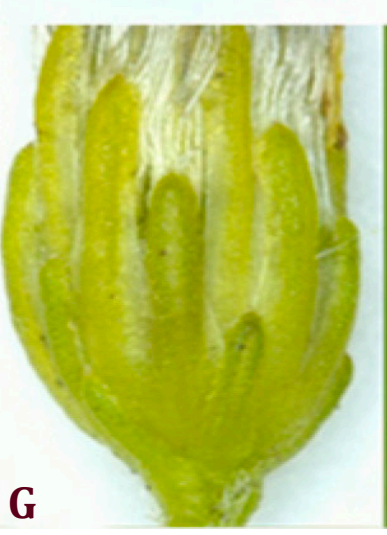

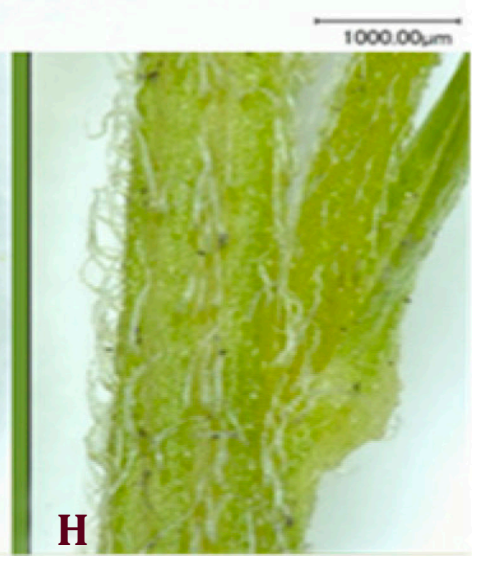

Figure 1 Morphology of generative organs of Solidago spp.

Panicles: A - S. gigantea, B - S. canadensis; heads: C - S. gigantea, D - S. canadensis; involucre: E - S. gigantea, G S. canadensis; rachis: F - S. gigantea, $\mathrm{H}-$ S. canadensis 
of aluminum chloride and $3 \mathrm{~mL}$ of distilled water. After $20 \mathrm{~min}$ in darkness, the absorbance at $430 \mathrm{~nm}$ was measured using the Spekol (1300, Analytik Jena, Germany). Quercetin (1-400 mg/L; $\mathrm{R}^{2}=0.9977$ ) was used as the standard. The results were expressed in $\mathrm{mg} / \mathrm{g}$ DM quercetin equivalent.

\section{Determination of morphometric characters}

To evaluate the morphometric characters, plants growing in the same agricultural background were selected, the sample consists of 50 heads for each species; studied parameters (length and diameter of the head, length of the involucre) were measured using a digital electron microscope Keyence VHX 1000.

\section{Statistical analysis}

Basic statistical analyses were performed using PAST 2.17. Data were analysed with ANOVA test and differences between means compared through the Tukey-Kramer test $(\mathrm{p}<0.05)$. The variability of all these parameters was evaluated using descriptive statistics.

\section{Results and discussion}

The total content of the saccharides in $S$. canadensis heads vary from $21.66 \pm 0.21$ to $31.07 \pm 0.68$ and the average was $27.33 \pm 0.54 \%$, with monosaccharides slightly less than half of this parameter (the average $12.05 \pm 0.11 \%$ ). Previously, we found that in the inflorescences of $S$. canadensis, fructose dominates in the composition of monosaccharides, all other monosaccharides were present in trace amounts (Shelepova et al., 2019a, b). In S. gigantea heads total content of the saccharides was 1.5 times lower $18.07 \pm 0.73 \%$, the content of monosaccharides was $7.39 \pm 0.15 \%$. According to the literature data, goldenrods are rich in acidic polysaccharides due to the presence of hexuronic acid and its derivatives, while the presence of acidic polysaccharides and polyphenols may be the result of the aggregation of polysaccharide chains with polyphenols (Liu et al., 2018). The resulting polyphenolic glycoconjugates have anticoagulant activity, which allows us to consider them as new sources of anticoagulant compounds (Pawlaczyk et al., 2009).

A wide range of phenolic compounds is present in the inflorescences and flowers of plants. These compounds are divided into two main groups: phenolic acids and flavonoids. Therefore, one of the goals of this study was to determine the content of phenolic compounds and flavonoids in the heads of two species of goldenrod.
The total content of phenolic compounds in the heads of $S$. canadensis varied from 101.17 to $115.38 \mathrm{mg}$ GAE/100 $\mathrm{g}$ and the average was $105.36 \pm 1.45 \mathrm{mg}$ GAE/100 g. In S. gigantea heads total content of phenolic compounds was 1.3-1.1 times lower ranging from 91.04 to $101.07 \mathrm{mg} \mathrm{GAE} / 100 \mathrm{~g}$ and the average was $98.41 \pm 1.71 \mathrm{mg} \mathrm{GAE} / 100 \mathrm{~g}$. This is significantly lower than the levels of phenolic acids (440-1200 mg/100 g) in the inflorescences of goldenrod growing in the more southern regions of Europe. But significantly higher than the levels of phenolic compounds found in honey from goldenrod (Jasicka-Misiak et al., 2018).

In the heads of Solidago, according to literature data, glycosides are represented mainly by glycosides of quercetin, kaempferol, and isorhamnetin (Zekič et al., 2021).

The total flavonoid content as quercetin equivalents in the heads of $S$. canadensis ranged from 49.3 to 64.1 (on average $58.2 \pm 0.17) \mathrm{mg} / 100 \mathrm{~g}$. The highest flavonoid content $(64.1 \pm 0.07 \mathrm{mg} / 100 \mathrm{~g})$ was observed in the sample collected in Moscow, while the lowest flavonoid content $(49.3 \pm 0.01 \mathrm{mg} / 100 \mathrm{~g})$ was found in the sample collected in the Pskov region. The flavonoid content in $S$. gigantea heads was slightly lower compared to $S$. canadensis heads and averaged $41.97 \pm 0.34$ $\mathrm{mg} / 100 \mathrm{~g}$.

Our results are significantly lower than the flavonoid levels found by Jasicka-Misiak et al. (2018). Thus, according to their data, the concentration of flavonoids in Solidago flowers was from 850 to $1380 \mathrm{mg} / 100 \mathrm{~g}$. The authors noted that the flavonoid content depends on climatic conditions. The highest levels of flavonoids were found in herbs collected in places with the greatest amount of sunlight. The authors suggest that the concentration of flavonoids in plants is proportional to the intensity of sunlight (Rosłon et al., 2014) and high temperature combined with low humidity (Karlová, 2006).

Our data on the comparison of the two species confirm the results of other studies. Thus, the analysis of flavonoids in extracts of the invasive $S$. canadensis revealed a significant increase in the content of rutin (quercetin-3-0-beta-rutinoside) in its composition compared to S. gigantea. The authors hypothesized that it is the synthesis of flavonoids that may determine the invasion strategy of $S$. canadensis. When entering the rhizosphere with exudates, flavonoids (mainly quercetin glycosides) can interact with ammonium. As a result, new compounds, phenol-ammonia complex, are formed. At low concentrations $(20 \mu \mathrm{g} / \mathrm{mL})$, these substances stimulate the formation of lateral and 


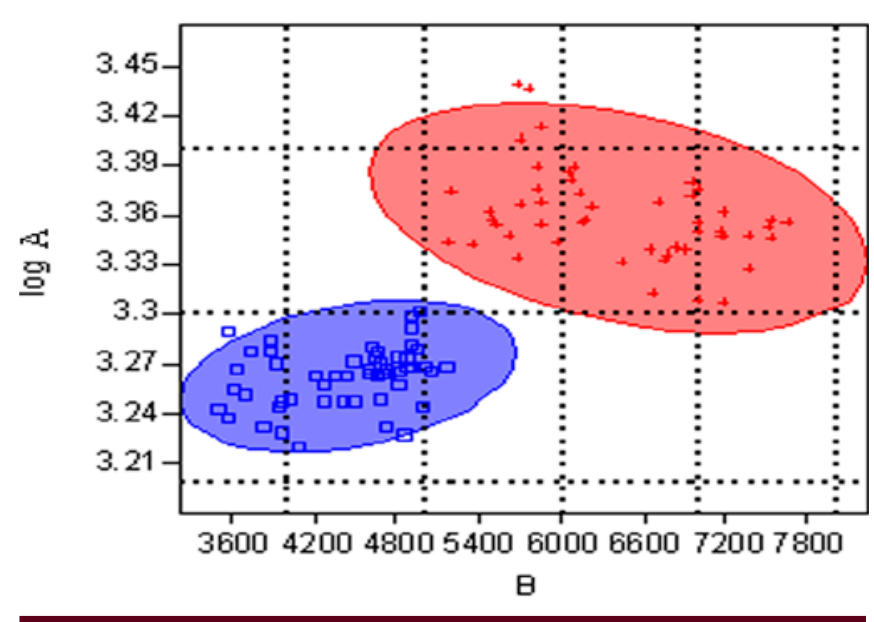

Figure 2 The head's size: $S$. canadensis (blue oval), and $S$. gigantea (red oval)

A - head's diameter; B - head's length

adventitious roots in plants, and in concentrations more than $100 \mu \mathrm{g} / \mathrm{mL}$ inhibit them. Enhanced synthesis and release of flavonoids, therefore, is an important element of the strategy for the biotransformation of a new habitat by alien plants species (Likhanov et al., 2021). The hypothesis about the determining influence of allelopathy on the invasive success of $S$. canadensis is also discussed by other scientists (Abhilasha et al., 2008; Li et al., 2011; Liao et al., 2011; Zhang et al., 2011; Baležentiene, 2015; Wang et al., 2016; Mozdzen et al., 2020).

For S. gigantea the head's length was $5.2-7.7 \mathrm{~mm}$ (in average $6.4 \pm 0.1 \mathrm{~mm} ; \mathrm{V}=11 \%$ ), the head's diameter 2.0-3.0 mm (2.3 $\pm 0.0 \mathrm{~mm} ; \mathrm{V}=9 \%)$, the involucre's length was $2.9-4.4 \mathrm{~mm}(3.7 \pm 0.1 \mathrm{~mm} ; \mathrm{V}=11 \%)$. For $S$. canadensis, these parameters are significantly lower: the head's length was $3.5-5.2 \mathrm{~mm}$ (in average $4.4 \pm 0.1 \mathrm{~mm} ; \mathrm{V}=11 \%$ ), the head's diameter $1.5-2.1 \mathrm{~mm}(1.8 \pm 0.0 \mathrm{~mm} ; \mathrm{V}=6 \%)$, the involucre's length was $2.6-3.9 \mathrm{~mm}(3.1 \pm 0.1 \mathrm{~mm}$; $\mathrm{V}=8 \%)$. However, the relative size of the involucre, on the contrary, is higher in S. canadensis - it is $70 \%$ of the head's length, while in S. gigantea the involucre is $60 \%$ of the head's length.

In Central Europe, S. canadensis occurs more frequently than S. gigantea and prefers drier and warmer habitats (Kabuce and Priede, 2021). It is not advisable to intentionally cultivate Solidago species as melliferous plants near the apiary. In some European countries, there is even a fine for this. Both $S$. canadensis and $S$. gigantea are aggressive invasive species and can displace valuable native honey plants from natural plant communities. In this case, the bee production in the apiary will decrease during the spring and summer periods.

\section{Conclusions}

In $S$. canadensis heads the total content of saccharides is 1.5 times higher, the content of phenolic compounds is 1.3 times higher, and the content of flavonoids is 1.4 times higher than in S. gigantea. A feature allowing the diagnosis of these species is the size of the heads: $S$. canadensis has smaller heads than $S$. gigantea $(4.4 \times 1.8$ vs. $6.4 \times 2.3 \mathrm{~mm})$.

\section{Conflicts of Interest}

The authors declare no conflict of interest.

\section{Ethical Statement}

This article does not contain any studies that would require an ethical statement.

\section{Funding}

This work was supported by grant SAIA (Bratislava, Slovakia) for the scholarship for the research during which the presented knowledge was obtained.

\section{Acknowledgments}

The publication was prepared with the active participation of researchers in international network AgrobioNet.

\section{References}

Abhilasha, D., Quintana, N., Vivanco, J., \& Joshi, J. (2008). Do allelopathic compounds in invasive Solidago canadensis s.l. restrain the native European flora? Journal of Ecology, 96, 993-1001. https://doi.org/10.1111/j.1365-2745.2008.01413.x

Amtmann, M. (2009). The chemical relationship between the scent features of goldenrod (Solidago canadensis L.) flower and its unifloral honey. Journal of Food Composition and Analysis, 23(1), 122-129. https://doi.org/10.1016/j.jfca.2009.10.001

Baležentiene, L. (2015). Secondary metabolite accumulation and phytotoxicity of invasive species Solidago canadensis L. during the growth period. Allelopathy Journal, 35, 217-226.

Gosudarstvennaya Farmakopeya Rossijskoj Federacii. (2015). XIII izdanie. [State Pharmacopoeia of the Russian Federation. XIII edition]. Moscow. [In Russian]

Jasicka-Misiak, I., Makowicz, E. \& Stanek, N. (2018). Chromatographic fingerprint, antioxidant activity, and colour characteristic of polish goldenrod (Solidago virgaurea L.) honey and flower. European Food Research and Technology, 244, 1169-1184. https://doi.org/10.1007/s00217-018-3034-3

Kabuce, N., \& Priede, N. (2021). NOBANIS - Invasive Alien Species Fact Sheet - Solidago canadensis. From: Online database of the european network on invasive Alien species - NOBANIS. 2010. Available online: www.nobanis.org (accessed on 19 September 2021). 
Karlová, K. (2006). Accumulation of flavonoid compounds in flowering shoots of Achillea collina Becker ex. Rchb. Alba during flower development. Horticultural Science, $33,158-162$.

Kuzmenko, A.N., Nesterova, O.V., Suleymanova, F. Sh., Matyushin, A.A., \& Krasnyuk, I.I. (Jr.). (2019). Modification of quantitative method of flavonoid determination in goldenrod canadensis (Solidago canadensis) herb. Vestnik of the Moscow University. Series 2. Chemistry., 60(1), 49-54.

Li, J., Ye, Y., Huang, H., \& Dong, L. (2011). Kaempferol-3-0$\beta$-D-glucoside, a potential allelochemical isolated from Solidago canadensis. Allelopathy Journal, 28, 259-266.

Liao, M., Xie, X., Peng, Y., \& Ma, A. (2011). Changes of Soil Microbiological Characteristics after Solidago canadensis L. Invasion Agricultural Science China, 10, 1064-1071.

Likhanov, A., Oliinyk, M., Pashkevych, N., Churilov, A., \& Kozyr, M. (2021). The role of flavonoids in invasion strategy of Solidago canadensis L. Plants, 10, 1748. https://doi.org/10.3390/plants10081748

Liu, J., Bai, R., Liu, Y., Zhang, X., Kan, J., \& Jin, C. (2018). Isolation, structural characterization and bioactivities of naturally occurring polysaccharide-polyphenolic conjugates from medicinal plants - A review. International Journal of Biological Macromolecules, 107, 2242-2250. https://doi.org/10.1016/j.ijbiomac.2017.10.097.

Mozdzen, K., Barabasz-Krasny, B., Zandi, P., Kliszcz, A., \& Puła, J. (2020). Effect of aqueous extracts from Solidago canadensis L. leaves on germination and early growth stages of three cultivars of Raphanus sativus L. var. radicula Pers. Plants, 9, 1549.

OFC.1.2.3.0019.15 Determination of saccharides by spectrophotometric method.

Patent No. 2406293 "Method for determination of watersoluble carbohydrates and starch content from a single sample.

Pawlaczyk, I., Czerchawski, L., Pilecki, W., Lamer-Zarawska, E., \& Gancarz, R. (2009). Polyphenolic-polysaccharide compounds from selected medicinal plants of Asteraceae and Rosaceae families: Chemical characterization and blood anticoagulant activity. Carbohydrate Polymers. 77(3), 568-575.

https://doi.org/10.1016/i.carbpol.2009.01.030
Rosłon, W., Osińska, E., Mazur, K., \& Geszprych, A. (2014). Chemical characteristics of European goldenrod (Solidago virgaurea L. subsp. virgaurea) from natural sites in central and eastern Poland. Acta Scientiarum Polonorum, 13, 55-65.

Shelepova, O., Vinogradova, Yu., Grygorieva, O., Vergun, 0., \& Brindza, J. (2019a). Invasive Solidago canadensis as a resource of valuable biological compounds. Slovak Journal of Food Sciences, 13(1), 280-286. https://doi.org/10.5219/1125

Shelepova, O., Vinogradova, Yu., Vergun, O., \& Brindza, J. (2019b). Antioxidant activity of herbal tea from leaves of Solidago canadensis L. In $4^{\text {th }}$ International scientific Conference Agrobiodiversity for improve the Nutrition, Health and Quality of Human and Bees Life. Nitra.

The most dangerous invasive species of Russia (TOP-100)/ Eds. Yu.Yu. Dgebuadze, V.G. Petrosyan, L.A. Khlyap. M.: KMK Scientific Press, 2018, 688 p. https://cloud.mail.ru/public/53SE/nQpQ2dLeP

Vinogradova, Yu.K., Mayorov, S.R., \& Choroon, L.V. (2010). Chernaya kniga flory Srednej Rossii. [Black Book of the Middle Russia flora. Moscow: GEOS]. Moskva: GEOS [In Russian]

Wang, C., Xiao, H., Zhao, L., Liu, J., Wang, L., Zhang, F., \& Du, D. (2016). The allelopathic effects of invasive plant Solidago canadensis on seed germination and growth of Lactuca sativa enhanced by different types of acid deposition. Ecotoxicology, 25, 555-562.

Yuan, Y.G., Wang, B., Zhang, S.S., Tang, J.J., Tu, C., Hu, S.J., Yong, J.W.H., \& Chen, X. (2013). Enhanced allelopathy and competitive ability of invasive plant Solidago canadensis in its introduced range. Journal of Plant Ecology, 6, 253-263.

Zekič, J., Vovk, I., \& Glavnik, V. (2021). Extraction and analyses of flavonoids and phenolic acids from Canadian goldenrod and Giant goldenrod. Forests, 12, 40. https://doi.org/10.3390/f12010040

Zhang, S., Zhu, W., Wang, B., Tang, J., \& Chen, X. (2011). Secondary metabolites from the invasive Solidago canadensis L. accumulation in soil and contribution to inhibition of soil pathogen Pythium ultimum. Applied Soil Ecology, 48, 280-286. 